\title{
DIMENSÕES DA TERCEIRIZAÇÃO E PRECARIEDADE DO TRABALHO NO SETOR ELÉTRICO BRASILEIRO
}

\author{
Mariana Bettega Braunert* \\ Igor Silva Figueiredo* *
}

\begin{abstract}
Este artigo tem como objetivo analisar algumas dimensões da terceirização e precariedade do trabalho em duas importantes companhias estatais de energia elétrica do Brasil: a Cemig (MG) e a Copel (PR). Através da análise de dados quantitativos e qualitativos, obtidos por meio de entrevistas realizadas principalmente com trabalhadores e dirigentes sindicais das empresas analisadas, constatamos um aumento crescente das contratações indiretas, que constitui uma das principais estratégias de redução de custos e aumento da produtividade. Entre os tantos aspectos que acompanham a precariedade do trabalho terceirizado, como o rebaixamento salarial e o enfraquecimento das lutas coletivas, ressaltamos o aumento do número de acidentes de trabalho, que se revela a dimensão mais preocupante do processo de terceirização de atividades que, por sua própria natureza, colocam os trabalhadores em situação de alto risco, como é o caso das desempenhadas por empresas do setor elétrico.

Palavras-chave: Setor Elétrico. Empresas Estatais. Terceirização. Precariedade. Acidentes de Trabalho.
\end{abstract}

\section{INTRODUÇÃO}

Entre as diversas transformações recentes que atingem o mundo do trabalho no novo contexto marcado pela flexibilidade das relações empregatícias, assume destaque o avanço da terceirização, que afeta trabalhadores dos mais diversos segmentos, tanto do setor público quanto do privado. O caráter precarizante desse processo tem sido atestado de maneira inequívoca por vários estudos brasileiros em sociologia do trabalho, que revelam a degradação que alcança quase todas as dimensões do trabalho terceirizado. Nesse contexto, o presente artigo analisa algumas dimensões do processo de terceirização em duas importantes companhias estaduais que atuam no ramo de

* Universidade Federal do Paraná (UFPR).

Rua Jaguariaíva, 512 - Caiobá. Cep: 83260-000. Matinhos - Paraná - Brasil. mbbraumert@gmail.com http://orcid.org/0000-0001-9580-8931

* * Faculdade de Direito de Itu (Faditu).

Av. Tiradentes, 1817 - Parque Industrial. Cep: 13309-864. Itu - São Paulo - Brasil. igor.figueiredo@gmail.com https://orcid.org/0000-0002-9532-1864 geração, transmissão e distribuição de energia elétrica no Brasil: a Companhia Energética de Minas Gerais (Cemig) e a Companhia Paranaense de Energia Elétrica (Copel). ${ }^{1}$

Para isso, utilizamos dados do volume de contratações e do número de acidentes de trabalho, os quais foram obtidos por meio do Departamento Intersindical de Estatística e Estudos Socioeconômicos (DIEESE), da Agência Nacional de Energia Elétrica (ANEEL) e dos departamentos de Recursos Humanos das referidas empresas. Analisamos também material qualitativo obtido em entrevistas em profundidade realizadas com 13 trabalhadores terceirizados e 4 representantes sindicais da Cemig, além de um técnico do DIEESE. No caso da Copel, entrevistamos 3 trabalhadores, 4 gestores, um ex-diretor da subsidiária de distribuição da

${ }^{1}$ Uma versão preliminar e modificada do presente artigo foi apresentada no $43^{\circ}$ Encontro Anual da ANPOCS, em Caxambu, em 2019. Os dados aqui apresentados são resultados parciais das pesquisas de tese de doutorado e dissertação de mestrado dos autores, intituladas "Empresas públicas, racionalidade privada? Um estudo sobre o trabalho nas companhias de economia mista do Paraná" (BRAUNERT, 2018) e "A terceirização em alta voltagem na Cemig: crônica da degradação do trabalho" (FIGUEIREDO, 2015). 
companhia e 2 representantes sindicais. Justifica-se o menor número de entrevistas com trabalhadores da companhia paranaense de energia porque a pesquisa realizada no Paraná abarcava originalmente também outras duas empresas estatais, a Companhia de Habitação do Paraná (Cohapar) e a Companhia de Saneamento do Paraná (Sanepar). Uma vez que utilizamos dados quantitativos do volume das contratações e dos números de acidentes de trabalho, as entrevistas visaram complementar e enriquecer a análise com informações de natureza mais qualitativa, razão pela qual consideramos a quantidade de entrevistas realizadas suficiente.

O presente texto está estruturado da seguinte forma: inicialmente, caracterizamos as empresas pesquisadas, enfatizando como são impactadas pelo advento do neoliberalismo no contexto de reestruturação produtiva e financeirização do capital. Em seguida, analisamos como a terceirização das atividades-fim cresce e passa a ser adotada de maneira irrestrita por essas companhias, de forma que a flexibilização da contratação da força de trabalho figura como a principal estratégia de redução de custo e aumento da produtividade. Evidenciamos as diversas dimensões da precarização do trabalho terceirizado nas empresas do setor elétrico pesquisadas e, na sequência, apresentamos dados sobre acidentes e mortes no trabalho envolvendo trabalhadores de seus quadros próprios e terceirizados. Sempre que possível, ปิ cotejamos os resultados encontrados com os N de outras pesquisas sobre terceirização e acidentes de trabalho no setor elétrico brasileiro, analisando em que medida os resultados por nós apresentados corroboram com os dessas ¿. pesquisas, além de aspectos das novas dimenî sões do trabalho terceirizado, sobretudo quan$\Rightarrow$ do envolve atividades do setor público.

\section{CARACTERIZAÇÃO DAS COM- PANHIAS PESQUISADAS E SUAS MUDANÇAS NO CONTEXTO NEO- LIBERAL}

A Cemig e a Copel são empresas estatais do setor elétrico dos estados de Minas Gerais e do Paraná, fundadas, respectivamente, em 1952 e 1954, que atuam nas áreas de geração, transmissão, distribuição e comercialização de energia elétrica. A Cemig companhia atua ainda na extração e comercialização do gás natural, por meio da Companhia de Gás de Minas Gerais (Gasmig), e no uso eficiente de energia, por meio da Efficientia. Já a Copel, atualmente a maior empresa do Paraná, efetua 70 mil novas ligações de energia a cada ano e atende praticamente $100 \%$ dos domicílios localizados nas áreas urbanas do estado e mais de 90\% dos localizados na área rural. Além disso, a Copel empregava, em julho de 2019, um total de 7.535 trabalhadores. A companhia está estruturada como holding, de forma que tem posse majoritária de ações de várias subsidiárias (Copel, [s. d.]). A Cemig também é estruturada como holding, de forma que é composta por mais de 174 empresas e tem participações em consórcios e fundo de participações, além de possuir ativos e negócios em 24 estados brasileiros e no Distrito Federal (Cemig, [s. d.]). A empresa possuía, no final de 2018, cerca de 6.000 empregados, o que a configura como a maior comercializadora de energia para clientes livres do país e um dos maiores grupos geradores (Cemig, [s. d.]).

Do ponto de vista jurídico, as companhias se constituem como sociedades de economia mista que integram a administração pública indireta dos estados de Minas Gerais e do Paraná, e, na qualidade de empresas estatais, têm campo de atuação situado no âmbito da ação empresarial do Estado. Embora adotem formato e perfil típicos de empresas, distinguem-se das entidades empresariais exclusivamente privadas, na medida em que, por 
sua vinculação ao Estado, possuem em alguma medida um viés social de atuação direcionado à população de baixa renda. ${ }^{2}$

Nas décadas recentes, especialmente desde 1990, com os avanços do neoliberalismo em um cenário marcado por globalização crescente, abertura de mercados, hegemonia do capital financeiro e forte competição internacional, observa-se uma mudança significativa no perfil e nos objetivos das empresas pesquisadas. Sabe-se que as chamadas "reformas neoliberais do Estado" ganharam força no Brasil durante os governos de Fernando Collor (1990-1992) e, principalmente, de Fernando Henrique Cardoso (1995-2002). Uma de suas principais propostas foi a privatização das empresas estatais, que alcançou não somente as empresas da União, mas também dos estados e municípios. Para o setor de produção de bens e serviços, no qual se inserem as empresas estatais, a reforma previa que o Estado só deveria intervir de forma subsidiária, propondo a privatização das empresas públicas e sociedades de economia mista, que, acusadas de "inchadas" e ineficientes, seriam supostamente mais eficientes se controladas pelo mercado e administradas privadamente. Conforme Vieira (2007, p. 85), "as reformas econômicas implementadas no Brasil, na década de 1990, impactaram profundamente a indústria de energia elétrica. Foi definida em 1990, como política de governo, a privatização de empresas sob controle da União e dos estados”.

Embora a Cemig e a Copel não tenham sido totalmente privatizadas, observa-se um processo de transferência do controle acionário dessas companhias para o setor privado e a adoção de uma dinâmica fundamentalmente orientada pelos imperativos da busca pelo lucro aos acionistas, ditados pela transferência do controle acionário à iniciativa privada, pro-

${ }^{2}$ No Brasil, historicamente, as empresas estatais serviram ao processo de acumulação e valorização do capital industrial (Abranches, 1979; Dain, 1980), cumprindo importante papel na implementação do projeto de modernização nacional-desenvolvimentista que se consolidou nas décadas seguintes a 1930. Nesse sentido, tanto a Cemig quanto a Copel desempenharam relevante função no desenvolvimento histórico e na modernização dos estados do Paraná e Minas Gerais. cesso que se intensifica sob a égide dos governos de orientação neoliberal. Conforme relatou um de nossos entrevistados sobre a Copel:

\footnotetext{
Hoje tem uma lógica muito forte de mercado, né! Mesmo sendo uma empresa estatal, o que se visa é o lucro. Então essas empresas têm que dar satisfação aos seus acionistas, não é só o Governo do Estado que é acionista, ele é majoritário mas tem outros. A gente percebe a influência que existe do mercado, da questão financeira dentro dessas empresas. Realmente o que se visa hoje é o lucro, é o grande objetivo das empresas, mesmo as estatais (Entrevista 23, realizada com o representante sindical dos trabalhadores da Copel, em dezembro de 2016).
}

Nesse cenário, a Copel abriu seu capital ao mercado de ações em abril de 1994 e tornou-se, em julho de 1997, a primeira empresa do setor elétrico brasileiro a ser listada na Bolsa de Valores de Nova Iorque. Atualmente, tanto a Copel quanto a Cemig possuem ações negociadas nas Bolsas de Valores de São Paulo, Nova Iorque e Madri, e ambas são empresas lucrativas, que apresentaram no primeiro trimestre de 2019 lucros líquidos de 797,2 milhões de reais (Cemig) ${ }^{3}$ e 506 milhões de reais (Copel). ${ }^{4}$ No que tange à composição acionária, embora o setor público ainda possua a maioria das ações ordinárias dessas companhias (que estão relacionadas ao direito de voto, isto é, poder de participação nas decisões da empresa), as ações preferenciais de ambas pertencem majoritariamente a acionistas do setor privado, que têm preferência no recebimento de lucros e dividendos. ${ }^{5}$ Os Quadros 1 e 2 sintetizam as informações gerais relativas às companhias pesquisadas e sua composição acionária:

\begin{tabular}{l}
3 Disponível em: https://mz-filemanager.s3.amazonaws. \\
com/716a131f-9624-452c-9088-0cd6983c1349/central-de- \\
-resultadoscentral-de-downloads/f7dd0efae010361cb7e- \\
\hline 7fa1ede2d33cd291f1460948718236b155f1ebb15b101/ \\
pressrelease_referente_ao_1t19.pdf. Acesso em: 31 ago. \\
2019. \\
${ }^{4}$ Disponível em: https://ri.copel.com/ptb/central-de-resul- \\
tados\#2019. Acesso em: 31 ago. 2019. \\
${ }^{5}$ Atualmente, a Cemig possui 149.988 acionistas e a Copel, \\
26.767.
\end{tabular} 
Quadro 1 - Dados gerais sobre as empresas pesquisadas

\begin{tabular}{|c|c|c|c|c|c|}
\hline & Ano de criação & $\begin{array}{l}\text { Número de } \\
\text { funcionários }\end{array}$ & $\begin{array}{l}\text { Número de } \\
\text { consumidores }\end{array}$ & $\begin{array}{c}\text { Lucro líquido no } 1^{\circ} \text { trimestre } \\
\text { de } 2019\end{array}$ & $\begin{array}{l}\text { Número de } \\
\text { acionistas }\end{array}$ \\
\hline CEMIG & 1952 & Aprox. 6.000 & 8,4 milhões & 797,2 milhões & 149.988 \\
\hline COPEL & 1954 & Aprox. 7.500 & 4,6 milhões & 506 milhões & 26.767 \\
\hline
\end{tabular}

Fonte: CEMIG $(2019)^{6}$ e COPEL (2019) ${ }^{7}$

Quadro 2 - Composição acionária da CEMIG e da COPEL em agosto 2019

\begin{tabular}{c|c|c|c|c}
\hline \multirow{2}{*}{} & \multicolumn{2}{|c|}{ CEMIG } & \multicolumn{2}{c}{ COPEL } \\
\cline { 2 - 5 } & Ações ordinárias (\%) & $\begin{array}{c}\text { Ações preferenciais } \\
\text { (\%) }\end{array}$ & Ações ordinárias (\%) & $\begin{array}{c}\text { Ações preferenciais } \\
\text { (\%) }\end{array}$ \\
\hline $\begin{array}{c}\text { Setor público (federal, } \\
\text { estadual e municipal) }\end{array}$ & 62,12 & 2,85 & 86,1 & 21,3 \\
\hline $\begin{array}{c}\text { Setor privado } \\
\text { (acionistas) }\end{array}$ & 37,88 & 97,15 & 13,7 & 78,7 \\
\hline
\end{tabular}

Fonte: CEMIG (2019) ${ }^{8}$ e COPEL (2019) ${ }^{9}$

* 0,2 \% das ações ordinárias da Copel pertencem a "outros"

Infere-se da análise das composições acionárias que a Cemig e a Copel privilegiam atualmente a distribuição de dividendos aos acionistas privados em detrimento de outros acionistas. Devido à tendência privatizante e à "reestruturação pró-mercado" (Vieira, 2007), essas companhias, assim como as demais empresas estatais do setor elétrico brasileiro, ${ }^{10}$ passaram a atuar em prol dos interesses dos investidores privados, adotando uma racionalidade caracterizada pela busca por lucro, em atendimento aos imperativos impostos pela lógica mercantil e financeira. Não se trata de afirmar que essas empresas assumiram um perfil empresarial e capitalista que antes não

ㄱ ${ }^{6}$ Disponível em: <http://www.cemig.com.br/pt-br/Pagiㄱ. nas/default.aspx $>$. Acesso em: 31 de ago. 2019.

ชิ 7 Disponível em: <https://www.copel.com/hpcopel/root/ 6 index.jsp $>$. Acesso em: 31 de ago. 2019.

I 8 Disponível em: <http://ri.cemig.com.br/governanca-corpo-

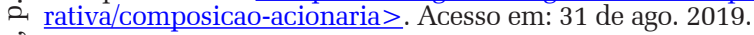

कீ ${ }^{9}$ Disponível em: <https://ri.copel.com/ptb/composicao-a$>$ cionaria $>$. Acesso em: 31 de ago. 2019.

: ${ }^{10}$ A reestruturação é uma realidade que afetou o setor elétrico brasileiro como um todo a partir da década de 1990, क quando as empresas do ramo passaram a adotar inovações técnicas e organizacionais com vista a obter maior efici-

Ti ência e competitividade. Nesse setor, segundo Scopinho

농 (2002, p. 20), "a reestruturação tem sido sustentada pela

necessidade de incrementar a produtividade, de aprimorar

a qualidade e de reduzir os custos de produção, para tor-

nar as empresas ainda não privatizadas mais atraentes aos olhos dos investidores". estatais atuaram essencialmente a serviço da acumulação do capital. Porém, se outrora seu âmbito de ação se voltava à valorização do capital industrial, atualmente elas passam a ser geridas pelos padrões do capital financeiro, o que eleva a outros patamares a necessidade de proporcionar lucro aos acionistas, imperativo que altera os padrões de gestão do trabalho.

Com isso, a lógica privada de geração de lucro passa a atuar do início ao fim da cadeia produtiva, e essas empresas passam a adotar medidas de redução de custos e aumento de produtividade, ótica na qual se inscreve o aumento crescente das terceirizações, que analisaremos a seguir.

\section{FLEXIBILIDADE DA CONTRATA- ÇÃO E AS DIMENSÕES DA PRE- CARIEDADE DO TRABALHO TER- CEIRIZADO}

$\mathrm{Na}$ esteira das transformações acima mencionadas, observa-se, tanto na Cemig quanto na Copel, um gradativo aumento dos processos de terceirização das atividades-fim e uma substituição progressiva dos trabalhadores do quadro próprio das empresas por força de trabalho terceirizada, sobretudo daqueles 
empregados que atuam em atividades de "linha de frente", como eletricistas e leituristas. $\mathrm{Na}$ Cemig, os eletricitários, que até o ano de 2005 pertenciam majoritariamente ao quadro próprio da empresa, em 2015 já eram predominantemente contratados de maneira terceirizada, de forma que a empresa em 2010 contava com aproximadamente 9.800 trabalhadores contratados diretamente e 13.250 terceirizados, para atender mais de sete milhões de consumidores. A Tabela 1 ilustra a composição da força de trabalho da Cemig em 2010, discriminando a quantidade de trabalhadores do quadro próprio e de terceirizados:

Tabela 1 - Composição da força de trabalho da

\begin{tabular}{l|c|c|c}
\multicolumn{4}{c}{ CEMIG em 2010 } \\
\hline $\begin{array}{l}\text { Força de } \\
\text { trabalho }\end{array}$ & $\begin{array}{c}\text { Trabalhadores } \\
\text { próprios }\end{array}$ & $\begin{array}{c}\text { Trabalhadores } \\
\text { terceirizados }\end{array}$ & Total \\
\hline $\begin{array}{l}\text { CEMIG } \\
\text { Distribuição }\end{array}$ & 7.609 & 11.627 & 19.236 \\
\hline $\begin{array}{l}\text { CEMIG } \\
\text { Geração / } \\
\text { Transmissão }\end{array}$ & 1.985 & 1.627 & 3.612 \\
\hline $\begin{array}{l}\text { CEMIG } \\
\text { Energética }\end{array}$ & 230 & 5 & 235 \\
\hline \multicolumn{3}{c}{ Força de trabalho total } & 23.083 \\
\hline
\end{tabular}

Fonte: Fundação Coge. Elaboração Igor Figueiredo.

No caso da Copel, o número total de trabalhadores da empresa aumentou de 7.151 em 2001 para 14.201 em 2016, contudo, nesse período, a quantidade de terceirizados cresceu em proporção significativamente maior que a dos contratados diretamente: enquanto o número de trabalhadores do quadro próprio aumentou de 5.854 para 8.531 (ou seja, nem sequer dobrou), o de terceirizados saltou de 1.497 para 5.670 (número quase quatro vezes maior). Em 2001, os terceirizados correspondiam a $20,36 \%$ do total de trabalhadores da Copel, percentual que foi convertido a quase 40\% em 2016, conforme dados da Tabela 2.

As tendências encontradas na Cemig e na Copel acompanham o que tem ocorrido na maioria das empresas estatais da União e dos estados: a redução das contratações diretas e o aumento crescente do número de trabalhadores terceirizados. Especialmente no caso do setor elétrico, estudos mostram que a substituição do quadro de funcionários próprio por força de trabalho terceirizada ocorre em praticamente todas as empresas públicas do segmento. Dados sobre a evolução da força de trabalho no setor elétrico brasileiro apontam que em 2003 ele era composto por 137.048 trabalhadores, dos quais 97.339 eram do quadro próprio das empresas e apenas 39.649 eram terceirizados. Já em 2010, quando o setor era composto por cerca de 232.000 trabalhadores,

Tabela 2 - Número de trabalhadores do quadro próprio e terceirizado da COPEL de 2001 a 2016

\begin{tabular}{|c|c|c|c|c|c|}
\hline Período & $\begin{array}{l}\text { Empregados do } \\
\text { quadro próprio }\end{array}$ & $\begin{array}{l}\text { Trabalhadores } \\
\text { terceirizados }\end{array}$ & Total & $\begin{array}{l}\text { \% de terceirizados } \\
\text { sobre o total }\end{array}$ & $\begin{array}{c}\text { \% de terceirizados } \\
\text { sobre o quadro } \\
\text { próprio }\end{array}$ \\
\hline 2001 & 5.854 & 1.497 & 7.351 & 20,36 & 25,57 \\
\hline 2002 & 5.857 & 1.696 & 7.553 & 22,45 & 28,96 \\
\hline 2003 & 6.293 & - & 6.293 & - & - \\
\hline 2004 & 6.749 & 2.003 & 8.752 & 22,89 & 29,68 \\
\hline 2005 & 7.704 & 2.292 & 9.996 & 22,93 & 29,75 \\
\hline 2006 & 8.119 & 2.227 & 10.346 & 21,53 & 27,43 \\
\hline 2007 & 8.347 & 2.237 & 10.584 & 21,14 & 26,80 \\
\hline 2008 & 8.405 & 5.090 & 13.495 & 37,72 & 60,56 \\
\hline 2009 & 8.560 & 5.089 & 13.649 & 37,28 & 593,45 \\
\hline 2010 & 8.907 & 5.225 & 14.132 & 36,97 & 58,66 \\
\hline 2011 & 9.400 & 5.220 & 14.620 & 35,70 & 55,53 \\
\hline 2012 & 9.468 & 5.524 & 14.992 & 36,85 & 58,34 \\
\hline 2013 & 8.647 & 5.622 & 14.269 & 39,40 & 65,02 \\
\hline 2014 & 8.592 & 5.895 & 14.487 & 40,69 & 68,61 \\
\hline 2015 & 8.628 & 6.457 & 15.085 & 42,80 & 74,84 \\
\hline 2016 & 8.531 & 5.670 & 14.201 & 39,93 & 66,46 \\
\hline
\end{tabular}

Fonte: DIEESE / ER-PR. Elaborado com base em dados do Balanço Social da empresa. 
estima-se que 104.857 deles eram contratados diretamente pelas empresas e a grande maioria (de 127.584) era composta por trabalhadores terceirizados. Ou seja, enquanto em 2003 a força de trabalho do chamado quadro próprio representava pouco mais de $71,1 \%$ do total dos eletricitários do país, em 2010 (apenas sete anos depois) houve uma inversão significativa nesses números, na medida em que a porcentagem de trabalhadores não terceirizados caiu de 71,1\% para 45,2\%. (Inácio; Tardeli, 2013, p. 464).

Nesse sentido, Druck (2017) analisa que a terceirização e a consequente substituição de servidores públicos por trabalhadores terceirizados é uma tendência do setor público como um todo, uma vez que não se localiza apenas nas atividades de apoio, mas também nas atividades-fim do Estado, tendo forte incidência nas empresas estatais. De forma genérica, as mais usuais concepções sobre terceirização, principalmente as encontradas nas literaturas liberais, conceituam o fenômeno como forma de otimizar o processo produtivo delegando os serviços de determinado setor da empresa contratante a uma empresa especializada na atividade. O destaque na palavra otimizar serve para evidenciar um dos vários termos vagos e ambíguos largamente utilizados nas literaturas e nos discursos empresariais, tais como flexibilização, adaptação, globalização e expressões inclusive não traduzidas do idioma de origem, mas que mantêm o eufemismo, como outsourcing (Chesnais, 1996). cipais mecanismos de precarização das relações de trabalho, tanto pela extensão com que tem sido adotada quanto por sua eficácia em garantir os níveis de produtividade e lucratividade das empresas (Marcelino, 2002), quase sempre por meio de jornadas extenuantes para os trabalhadores e trabalhadoras, diminuição de direitos e benefícios e rebaixamento salarial. Entretanto, não apenas no Brasil, mas também em grande parte do mundo, o debate sobre terceirização é extremamente polifônico e envolve inúmeras tentativas de definição do termo, além de disputas em torno dos efeitos da terceirização para trabalhadores e trabalhadoras em várias áreas das ciências sociais.

Concordamos com os mais recentes estudos sobre os efeitos da terceirização no Brasil que demonstraram suas consequências danosas e precarizantes. Os estudos produzidos nas últimas duas décadas sobre terceirização e precarização do trabalho evidenciam, pois, que esses processos se desenvolvem paralelamente de maneira quase inevitável e levam à classe trabalhadora inúmeros impactos negativos da terceirização, como atestado por uma abundante quantidade de pesquisas que apontam um sentido precarizante nas relações de trabalho terceirizadas (Druck, 1999, 2017; Druck; Borges, 2002; Marcelino, 2002, 2008, 2015).

A terceirização, apesar de suas múltiplas formas de manifestação, tem como objetivos fundamentais a redução de custos, a flexibilidade organizacional e a partilha dos riscos do negócio com outro agente econômico, como estratégia de enfrentamento do capitalismo financeiro, no qual as empresas estão expostas a uma maior concorrência devido à desregulação da economia e ao baixo e instável crescimento do produto. Essas características, com algumas exceções, no caso brasileiro, permitem vincular a terceirização à flexibilização das relações de trabalho e à precarização (Krein, 2007). Como sintetiza Druck (2017, p. 59):

\footnotetext{
Os estudos nos últimos 25 anos sobre terceirização no Brasil foram unânimes em revelar a degradação do trabalho em todas as suas dimensões: no desrespeito aos direitos trabalhistas, nas más condições de trabalho, nos baixos salários, na piora das condições de saúde e nos maiores índices de acidentes e na vulnerabilidade política dos trabalhadores que, dispersos e fragmentados, têm dificuldades para se organizar coletivamente.
}

Nos casos observados, tanto na Cemig quanto na Copel os trabalhadores terceirizados costumam receber metade do salário dos contratados diretos, além de não terem acesso aos mesmos benefícios, como vale alimentação, participação nos lucros da empresa, remuneração no modelo de Participação nos Lucros e 
Resultados (PLR) e convênio médico. Apesar de receberem menos, trabalham mais, na medida em que desempenham extensas e exaustivas jornadas de trabalho de cerca de 10 horas por dia, com metas diárias de ordens de serviço a serem cumpridas, intensas cobranças por produtividade e pouco tempo de descanso, o que os torna ainda mais vulneráveis a acidentes de trabalho. No caso da Cemig, durante a pesquisa foi possível identificar trabalhadores que executam a mesma função e têm o mesmo cargo (eletricitário de linhas e redes), mas não têm os mesmos direitos por serem contratados de maneiras diversas. Ou seja, trata-se de trabalhadores que executam o mesmo trabalho, mas são diferenciados pela forma jurídica de contratação a que estão submetidos.

No ano de 2014, a Cemig foi responsabilizada pelo Ministério Público do Trabalho (MPT) e pelo Ministério do Trabalho e Emprego (MTE) em função do flagrante de 179 trabalhadores em condições análogas à de escravidão. Esses trabalhadores eram submetidos a jornadas de mais de 11 horas por dia, dentre outros abusos. De acordo com o MPT, dos 179 trabalhadores, 82 eram migrantes, principalmente do interior de Minas Gerais, e estavam em alojamentos em condições degradantes: "sete casas onde moravam os funcionários, em Belo Horizonte, não tinham armários e estavam cheias de lixo e entulho" (Coutinho, 2014). Alguns relatos colhidos por meio das entrevistas também nos trazem uma dimensão bastante concreta e, de certa forma, dramática, do que significa o trabalho terceirizado nas atividades próprias do setor elétrico. Um ex-diretor da Copel Distribuição, afastado do cargo por contrariar interesses de uma grande empreiteira que realizava a atividade de leitura, descreveu detalhes do episódio, contando a precariedade que atingiu a condição de trabalho dos empregados leituristas quando essa importante atividade foi terceirizada. Segue o relato:

Sabe o que é leitura? É o leiturista que vem ler o medidor da luz. É uma atividade fundamental. Dela depende o faturamento da empresa. Dela depende a própria imagem da Copel. Aquele é um funcionário que visita todos os consumidores uma vez por mês. O que que chega pra mim? Queixas de consumidores reclamando que o leiturista pediu por favor um prato de comida, porque não tinha vale-refeição pra comer. Que o leiturista estava de chinelo de dedo no frio. Que o leiturista não estava uniformizado. Coisas assim do tipo "o leiturista não sabe fazer o seu trabalho”. E eu, com base nisso, esperei o vencimento dos contratos, porque eu respeito os contratos e os contratos estavam pra vencer, e disse "eu quero a minha Copel de volta, leitura vai ser novamente da companhia” (Entrevista 12, realizada com o ex-diretor da Copel, em outubro de 2016).

Além de baixos salários, falta de acesso a benefícios e intensas jornadas de trabalho, a condição de terceirizado é marcada, ainda, pela instabilidade, pois a rotatividade de trabalhadores é alta e, consequentemente, eles permanecem menos tempo no emprego que os trabalhadores do quadro próprio das empresas analisadas. Na Cemig, as condições de trabalho a que são submetidos os trabalhadores terceirizados deixam marcas irreversíveis e geram uma grande insegurança em quem ancora a vida na profissão de eletricitário. A insegurança dos trabalhadores terceirizados, se comparada à segurança dos trabalhadores do quadro próprio da Cemig, ${ }^{11}$ é um aspecto de diferenciação chocante observado na investigação empírica.

A maior instabilidade a que está submetido o trabalhador terceirizado possui uma série de consequências, entre as quais vale mencionar a maior subordinação e o enfraquecimento da luta coletiva. No que tange ao primeiro aspecto, uma gerente entrevistada da Copel destacou que a terceirização tende a aumentar na companhia "porque é mais barato" e a tendência é reduzir custos. Talvez pela

11 Os trabalhadores das empresas estatais, embora não sejam estatutários e tenham contrato de trabalho regido pelas normas da Consolidação das Leis do Trabalho (CLT), ingressam nas companhias mediante realização de concurso público, o que lhes confere uma relativa estabilidade no emprego, superior à dos trabalhadores celetistas das empresas privadas. Ou seja, mesmo que sejam celetistas e não estatutários, os trabalhadores contratados diretamente pela Cemig e pela Copel raramente são demitidos, o que os leva a dispor de uma condição relativamente estável no emprego, em contraposição à situação dos trabalhadores terceirizados, marcada por incerteza e instabilidade. 
posição que ocupa na empresa (de gerente), ela tende a reproduzir o discurso empresarial hegemônico de ataque aos direitos e proteções vinculados ao trabalho, afirmando que o empregado próprio é "cheio de chatice" e que o terceirizado costuma obedecer às ordens com mais facilidade. Quando indagada sobre a terceirização, ela afirmou:

Tem uma tendência de aumentar, porque é mais barato. E porque eu já ouvi falar de algumas pessoas que inclusive você tem menos problema com empregado quando você terceiriza, no sentido de satisfação mesmo. Você pede pra um terceiro executar tal atividade ele vai lá e executa, você pede pra um empregado próprio ele pergunta por que que tem que fazer, e não sei o que... O empregado próprio ele é cheio de chatice. Como a nossa característica hoje tá assim de reduzir custo... (Entrevista 20, realizada com o gerente da Copel, em janeiro de 2017).

Esse depoimento revela, portanto, uma importante dimensão, não muito abordada pela literatura do trabalho terceirizado, relativa ao controle sobre o trabalhador. Uma vez que o vínculo do trabalhador terceirizado é mais instável, ele tende a se subordinar com mais facilidade a suas chefias, que parecem ver vantagem na fragilidade da condição, pois obtêm maior colaboração dos assalariados. Quanto aos impactos da terceirização sobre a luta coletiva, é vasta a literatura que corrobora com a ideia de que a terceirização fragmenta, divide e dificulta a organização sindical dos trabalhado¿ res (Ramalho, 1997; Antunes, 2010). Segundo ڤิ Krein (2007, p. 205), “a terceirização tende a ปี pulverizar a base de representação e a diminuir จิ o poder do sindicato principal, constituindo-se e em mecanismo de pressão para a viabilização $\stackrel{-}{\rightarrow}$ da flexibilização das relações de trabalho".

É interessante notar que os trabalhadores terceirizados da Cemig, apesar de serem submetidos a inúmeras mazelas no dia a dia, também demonstram resistência, criatividade e esperança em tentativas de oposição a esse processo. Nesse sentido, identificamos que os trabalhadores, para cobrar atrasos salariais e protestar contra assédios, práticas autoritárias ou descumprimento de cláusulas contratuais em geral, se reúnem sob uma liderança (em muitos casos independente dos sindicatos) e realizam "boicotes solidários", que são rápidas paralisações e atrasos no início do expediente, ou, em episódios mais raros, fazem greves de um ou dois dias. Ou seja, se é verdade que a terceirização fragmenta e dificulta a luta dos trabalhadores, não se pode dizer que eles respondem de maneira totalmente apática e passiva ao processo, o que torna fundamental questionar também quais as formas de resistências identificadas, sejam elas individuais ou coletivas, objetivas ou subjetivas.

Note-se, por fim, que tanto na Cemig quanto na Copel, o aumento da terceirização veio acompanhado não só da precarização das condições de trabalho, mas também de uma queda na qualidade dos serviços prestados. A respeito disso, o trabalhador $\mathrm{P}$, engenheiro da Copel, ponderou que o custo da terceirização é uma queda na qualidade do serviço da companhia, já que o funcionário da terceirizada é um prestador de serviço e a rotatividade da força de trabalho é alta. Segundo ele, a terceirização deve ser feita com muito cuidado porque "você nunca vai ter um serviço de qualidade terceirizado", avaliação dita de uma maneira chula. Ele explicou o motivo: "o funcionário da terceirizada é um prestador de serviço, hoje é ele, amanhã é outro". Um dos gerentes entrevistado reconheceu a maior qualidade dos serviços prestados pelos trabalhadores do quadro próprio da Copel do que pelos funcionários das empresas terceirizadas, já que estes últimos são menos qualificados e sofrem mais intensivamente cobranças por produtividade:

Se você na tua residência ficar sem energia e chamar a Copel, vai chegar uma pessoa lá pra atender. Pode ser um terceiro ou pode ser um funcionário próprio. O funcionário próprio vai te atender com mais qualidade, vai falar as coisas com mais propriedade, ele talvez tenha mais facilidade pra encontrar o problema. É mais qualificado. O funcionário terceirizado vai chegar ali e vai fazer o que dá pra terminar logo e ir para o próximo porque ele tá ganhando por pro- 
dutividade (Entrevista n 18, realizada com o gerente da Copel, em dezembro de 2016).

$\mathrm{Na}$ Cemig, foi igualmente detectada uma nítida piora no atendimento aos consumidores com o avanço dos processos de terceirização, comprovada pela negligência da estatal em relação aos indicadores de qualidade estabelecidos pela ANEEL, como o DEC (aumento por tempo médio sem energia por consumidor) e o FEC (aumento na frequência de interrupções por consumidor), que a companhia mineira não tem conseguido cumprir. Portanto, a terceirização nas empresas estatais, mais do que precarizar as condições de trabalho, parece acarretar também considerável queda na qualidade dos serviços prestados, o que gera consequências negativas para toda a sociedade. Assim, ao mesmo tempo em que degrada as relações de trabalho, ela também piora a prestação de serviços e o oferecimento de bens públicos para a população.

Nesse sentido, Druck (2017) observa que a terceirização no serviço público, além de uma forma de privatização, é um dos mecanismos mais eficientes de desmonte do conteúdo social do Estado por meio do ataque ao funcionalismo público. Por essa razão, considera que a precarização do trabalho no setor público tem uma importante singularidade: "por se tratar de uma força de trabalho cujo valor de uso é produzir bens públicos e, portanto, servir à sociedade, o seu rebaixamento ou sua redução ou mesmo a sua extinção geram implicações imediatas e plenamente visíveis ao conjunto da sociedade" (Druck, 2017, p. 85). Esse aspecto da precarização dos serviços prestados por empresas públicas em decorrência da terceirização do trabalho também é enfatizado por Valente (2009, p. 105):

No caso do setor público em especial, o processo de terceirização assume contornos mais graves: para além de precarizar os direitos do/a trabalhador/a, o que por si só é deletério, a terceirização precariza a prestação de um serviço que se pretende público, universal e de boa qualidade. É o caso da saúde, da educação, do fornecimento de água, saneamento, energia elétrica, só para citar aqueles que dizem respeito à manutenção da vida e da dignidade humana.

Cabe enfatizar o caráter privatizante que a terceirização assume no setor público, em um contexto de avanço das políticas neoliberais de viés privatista que constantemente ameaçam as empresas estatais brasileiras, sob o falacioso argumento de que a iniciativa privada seria mais eficiente que o Estado na prestação de serviços como fornecimento de energia elétrica e saneamento básico. No caso da Copel, ela sofreu forte ameaça de privatização no início dos anos 2000, período em que Jaime Lerner (1995-2002) esteve à frente do governo do estado do Paraná. ${ }^{12}$ Atualmente, uma das mais importantes empresas do setor elétrico brasileiro, a Eletrobras, encontra-se em situação semelhante, isto é, em vias de ser privatizada. A qualidade dos serviços prestados pelas empresas estatais de energia elétrica, somada à sua lucratividade, evidencia que as privatizações atendem mais aos interesses do mercado do que ao interesse público da sociedade como um todo.

Na seção subsequente, abordaremos o aspecto que pode ser considerado o mais preocupante da terceirização irrestrita no caso das companhias estatais, especialmente distribuidoras de energia elétrica: o aumento significativo na quantidade de acidentes fatais de trabalho.

\section{A TERCEIRIZAÇÃO EM ALTA VOLTAGEM E OS ACIDENTES DE TRABALHO NO SETOR ELÉTRICO}

Quanto às atividades com natureza de alto risco ao trabalhador, como o trabalho do eletricitário, a terceirização tem como consequência mais perversa o aumento do número de acidentes e mortes no trabalho.

Os números apresentados na Tabela 3

${ }^{12}$ A tentativa de privatização da Copel em 2001 foi frustrada, ao que tudo indica, por conta da intensa mobilização popular contrária à medida, somada ao ambiente de instabilidade econômica que se instalou após o ataque terrorista às Torres Gêmeas, em Nova Iorque, em 11 de setembro de 2001 
mostram o alto risco envolvido nas atividades do setor elétrico, dados os altos índices de acidentes de trabalho registrados entre 1999 e 2017, tanto no Brasil quanto nos estados pesquisados:

Tabela 3 - Número de acidentes de trabalho no setor elétrico brasileiro, em Minas Gerais e no Paraná de 1999 a 2017

\begin{tabular}{l|c|c|c}
\multicolumn{4}{c}{ Paraná de 1999 a 2017 } \\
\hline $\mathbf{1 9 9 9}$ & Brasil & $\begin{array}{c}\text { Minas Gerais } \\
\text { (MG) }\end{array}$ & Paraná (PR) \\
\hline $\mathbf{2 0 0 0}$ & 2708 & 353 & 179 \\
\hline $\mathbf{2 0 0 1}$ & 2913 & 283 & 141 \\
\hline $\mathbf{2 0 0 2}$ & 2295 & 304 & 142 \\
\hline $\mathbf{2 0 0 3}$ & 2401 & 335 & 153 \\
\hline $\mathbf{2 0 0 4}$ & 2270 & 323 & 216 \\
\hline $\mathbf{2 0 0 5}$ & 2675 & 346 & 225 \\
\hline $\mathbf{2 0 0 6}$ & 2853 & 269 & 226 \\
\hline $\mathbf{2 0 0 7}$ & 3080 & 262 & 284 \\
\hline $\mathbf{2 0 0 8}$ & 3304 & 281 & 305 \\
\hline $\mathbf{2 0 0 9}$ & 3207 & 311 & 247 \\
\hline $\mathbf{2 0 1 0}$ & 2919 & 244 & 267 \\
\hline $\mathbf{2 0 1 1}$ & 2920 & 180 & 238 \\
\hline $\mathbf{2 0 1 2}$ & 2988 & 152 & 255 \\
\hline $\mathbf{2 0 1 3}$ & 3035 & 159 & 305 \\
\hline $\mathbf{2 0 1 4}$ & 2821 & 198 & 267 \\
\hline $\mathbf{2 0 1 5}$ & 2851 & 168 & 251 \\
\hline $\mathbf{2 0 1 6}$ & 2661 & 160 & 224 \\
\hline $\mathbf{2 0 1 7}$ & 2457 & 113 & 188 \\
\hline & & &
\end{tabular}

Fonte: Previdência Social (DATAPREV). Elaboração: Igor Figueiredo

* CNAE 95 Grupo: 401 Produção e Distribuição de Energia Elétrica (19992005). CNAE 2.0 Classe: 35115 Geração de Energia Elétrica; 35123 Transmissão de Energia Elétrica; 35131 Comércio Atacadista de Energia Elétrica; 35140 Distribuição de Energia Elétrica (2006-2017).

Na série histórica apresentada na Tabela 3, iniciada no ano de 1999 (pois não havia dados anteriores a esse ano disponíveis no banco de dados da previdência social), nota-se o alto índice de acidentes de trabalho no setor elétri¿. co brasileiro. Constata-se que, na série históri§ึ ca, aparentemente, não há padrão de evolução no número de acidentes no Brasil, na medida em que ele é alto em praticamente todo o período analisado. Em quase todos os anos da série, o número de acidentes variou entre 2.200 e 3.000 ocorrências; em 2007, houve o pico de acidentes da série, com 3.304 ocorrências, e, em 2003, aconteceram 2.270 incidentes, o menor número da série. Ou seja, não há um padrão de aumento ou diminuição de acidentes ao longo dos anos. Nesse cenário de acidentes totais unificados, não é possível distinguir explicitamente a quantidade de acidentes de trabalhadores do quadro próprio das empresas daqueles ocorridos com trabalhadores terceirizados. No entanto, estudos realizados pelo DIEESE (2006; 2010) já apontavam grande transformação no perfil do eletricitário brasileiro a partir de meados da década de 1990. De acordo com o DIEESE (2010, p. 3), “o quadro de trabalhadores, de acordo com informação captada pela Relação Anual de Informações Sociais (RAIS) foi reduzido a quase metade num intervalo de menos de uma década. A hipótese era que essa redução possuía forte relação com o processo de terceirização". Ao investigar o porquê de tal redução, o DIEESE (2010) constatou que as atividades exercidas pelas empreiteiras ou empresas contratadas para executar a prestação de serviço no setor elétrico frequentemente não se enquadram nos códigos da Classificação Nacional de Atividades Econômicas (CNAE) específicos do setor elétrico, como atividades de geração, transmissão, comércio atacadista e distribuição de energia elétrica.

Conforme foi atestado pelos estudos do DIEESE sobre o setor elétrico brasileiro em geral, as Tabelas 1 e 2 deste artigo demonstram que o processo contínuo de substituição da força de trabalho própria pela terceirizada também ocorreu na Cemig e na Copel. No entanto, as fontes de dados utilizadas na elaboração das tabelas supracitadas foram o próprio DIEESE e a Fundação Coge, fundação patronal que agrupa as empresas de energia elétrica e elabora estatísticas sobre o setor. Quanto aos acidentes de trabalho fatais, eles estão mais concentrados nas atividades de distribuição de energia elétrica, que emprega a maior parte da força de trabalho, inclusive terceirizada: 
Tabela 4 - Número de óbitos no setor elétrico brasileiro 2006-2017, por CNAE*

\begin{tabular}{|c|c|c|c|c|}
\hline Ano & $\begin{array}{c}35115 \text { - } \\
\text { Geração } \\
\text { de Energia } \\
\text { Elétrica }\end{array}$ & $\begin{array}{c}\text { 35123 - } \\
\text { Transmissão } \\
\text { de Energia } \\
\text { Elétrica }\end{array}$ & $\begin{array}{c}35131- \\
\text { Comércio } \\
\text { Atacadista } \\
\text { de Energia } \\
\text { Elétrica }\end{array}$ & $\begin{array}{c}35140 \text { - } \\
\begin{array}{c}\text { Distribuição } \\
\text { de Energia } \\
\text { Elétrica }\end{array} \\
\end{array}$ \\
\hline 2006 & 10 & 4 & 0 & 16 \\
\hline 2007 & 5 & 5 & 0 & 13 \\
\hline 2008 & 4 & 0 & 0 & 21 \\
\hline 2009 & 5 & 3 & 0 & 5 \\
\hline 2010 & 4 & 2 & 0 & 9 \\
\hline 2011 & 6 & 5 & 0 & 20 \\
\hline 2012 & 2 & 2 & 0 & 8 \\
\hline 2013 & 11 & 6 & 1 & 9 \\
\hline 2014 & 9 & 4 & 1 & 5 \\
\hline 2015 & 9 & 5 & 0 & 13 \\
\hline 2016 & 4 & 4 & 0 & 7 \\
\hline 2017 & 6 & 3 & 0 & 11 \\
\hline Total & 75 & 43 & 2 & 137 \\
\hline
\end{tabular}

Fonte: Previdência Social - Anuário Estatístico de Acidentes do Trabalho de 2008, 2009, 2010, 2011, 2012, 2013, 2014, 2015, 2016 e 2017. Elaboração: Igor Figueiredo.

* CNAE 2.0 Classe: 35115 Geração de Energia Elétrica; 35123 Transmissão de Energia Elétrica; 35131 Comércio Atacadista de Energia Elétrica; 35140 Distribuição de Energia Elétrica.

Conforme observa-se na Tabela 4, com informações mais desagregadas, os dados extraídos da previdência social por meio da CNAE 2.0 mostram que o número de acidentes fatais no setor elétrico brasileiro obedece a certa tendência de continuidade ao longo dos anos, com alguns picos e variações quanto ao número de acidentes durante a série histórica apresentada. Segundo os dados da Tabela 4, a maioria dos acidentes fatais do setor elétrico nacional ocorre na atividade de distribuição energética que soma 137 mortes de trabalhadores no Brasil na série de 2006 a 2017. Isso se deve, sobretudo, ao fato de que na atividade de distribuição energética se concentra a maior parte de trabalhadores do setor elétrico, tanto em números absolutos - incluindo próprios e terceirizados - como na proporção com os outros setores de atividades das empresas.

Quanto à relação entre funcionários do quadro próprio e terceirizados, estes são mais numerosos do que aqueles, atualmente. Como pode ser visto na Tabela 1 sobre a Cemig, no ano de 2010, o número de trabalhadores terceirizados (11.627) nas atividades de trans- missão superava os do quadro próprio (7.609). É justamente no setor de atividade de distribuição energética que os eletricistas e leituristas - funções que mais sofrem acidentes em empresas elétricas - são lotados. Assim como a Tabela 3, a Tabela 4 não apresenta dados desagregados para acidentes com a força de trabalho própria e terceirizada. No entanto, em nossas investigações de campo, constatamos - corroborando com o estudo do DIEESE (2010) acerca da dificuldade de localização das empresas que prestam serviço para o setor elétrico na CNAE - que é no setor de distribuição que se concentra a maior parte de empresas terceirizadas que realizam prestação de serviço para concessionárias do setor elétrico brasileiro; consequentemente, é também no setor de atividade de distribuição que se concentra a maior parte de trabalhadores terceirizados e a maior quantidade de acidentes e óbitos em empresas de eletricidade. É o que foi verificado quando consultamos os dados da própria agência que regula o setor elétrico, a ANEEL, conforme as Tabelas 5 e 6 a seguir.

Dados da ANEEL retratam que, entre 2009 e 2018, a quantidade de acidentes fatais com trabalhadores terceirizados do setor elétrico brasileiro foi 5 vezes maior que os envolvendo trabalhadores do quadro próprio das empresas. Por exemplo, apenas no setor de atividade de distribuição energética, enquanto trabalhadores do quadro próprio sofreram 88 acidentes fatais, entre os terceirizados, esse número foi de 466:

Os dados indicam que, em uma série histórica de apenas dez anos, 466 trabalhadores terceirizados perderam a vida durante a realização da atividade laboral. Cumpre salientar que é também extremamente alta e assombrosa a quantidade de trabalhadores do quadro próprio das empresas de eletricidade que perderam a vida em uma década; afinal, não cabe 
Tabela 5 - Número de óbitos no setor elétrico em Minas Gerais (MG) e no Paraná (PR), trabalhadores é ainda por $\mathrm{CNAE}^{*}$

\begin{tabular}{l|c|c|c|c|c|c|c|c}
\hline \multirow{2}{*}{ Ano } & \multicolumn{2}{|c|}{$\begin{array}{c}\text { 35115 - } \\
\text { Geração de } \\
\text { Energia Elétrica }\end{array}$} & \multicolumn{2}{c|}{$\begin{array}{c}\text { 35123 - } \\
\text { Transmissáo de } \\
\text { Energia Elétrica }\end{array}$} & $\begin{array}{c}\text { 35131 - } \\
\text { Comércio } \\
\text { Atacadista de } \\
\text { Energia Elétrica }\end{array}$ & \multicolumn{2}{c}{$\begin{array}{c}\text { 35140 - } \\
\text { Distribuiçáo de } \\
\text { Energia Elétrica }\end{array}$} \\
\cline { 2 - 9 } & MG & PR & MG & PR & MG & PR & MG & PR \\
\hline 2006 & 1 & 1 & 0 & 1 & 0 & 0 & 1 & 1 \\
\hline 2007 & 0 & 0 & 0 & 2 & 0 & 0 & 0 & 0 \\
\hline 2008 & 0 & 0 & 0 & 0 & 0 & 0 & 2 & 1 \\
\hline 2009 & 0 & 0 & 1 & 0 & 0 & 0 & 1 & 0 \\
\hline 2010 & 0 & 2 & 0 & 0 & 0 & 0 & 1 & 1 \\
\hline 2011 & 0 & 0 & 0 & 0 & 0 & 0 & 0 & 1 \\
\hline 2012 & 0 & 0 & 0 & 0 & 0 & 0 & 0 & 0 \\
\hline 2013 & 1 & 1 & 0 & 0 & 0 & 0 & 1 & 1 \\
\hline 2014 & 0 & 2 & 0 & 0 & 0 & 0 & 0 & 0 \\
\hline 2015 & 0 & 1 & 0 & 0 & 0 & 0 & 0 & 1 \\
\hline 2016 & 3 & 0 & 0 & 0 & 0 & 0 & 0 & 0 \\
\hline 2017 & 1 & 0 & 0 & 0 & 0 & 0 & 0 & 0 \\
\hline Total & $\mathbf{6}$ & $\mathbf{7}$ & $\mathbf{1}$ & $\mathbf{2}$ & $\mathbf{0}$ & $\mathbf{0}$ & $\mathbf{6}$ & $\mathbf{6}$ \\
\hline
\end{tabular}
maior.

Fonte: Previdência Social - Anuário Estatístico de Acidentes do Trabalho de 2008, 2009, 2010, 2011, 2012, 2013, 2014 2015, 2016 e 2017. Elaboração: Igor Figueiredo.

* CNAE 2.0 Classe: 35115 Geração de Energia Elétrica; 35123 Transmissão de Energia Elétrica; 35131 Comércio Atacadista de Energia Elétrica; 35140 Distribuição de Energia Elétrica.

aceitar como razoável nenhuma quantidade de mortes no trabalho. Outrossim, a questão mais notória e importante dos dados é a diferença abissal entre números de mortos do quadro próprio e de terceirizados. Quando atentamos para a realidade das empresas pesquisadas, a diferença entre o número de acidentes desses

Tabela 6 - Número de óbitos no setor elétrico com a força de trabalho própria e terceirizada no Brasil de 2009 A 2018*

\begin{tabular}{|c|c|c|}
\hline & $\begin{array}{l}\text { Funcionários do } \\
\text { quadro próprio }\end{array}$ & $\begin{array}{l}\text { Funcionários } \\
\text { terceirizados }\end{array}$ \\
\hline 2009 & 4 & 58 \\
\hline 2010 & 8 & 71 \\
\hline 2011 & 19 & 58 \\
\hline 2012 & 8 & 51 \\
\hline 2013 & 12 & 41 \\
\hline 2014 & 7 & 50 \\
\hline 2015 & 11 & 55 \\
\hline 2016 & 4 & 27 \\
\hline 2017 & 9 & 37 \\
\hline 2018 & 6 & 18 \\
\hline Total & 88 & 466 \\
\hline
\end{tabular}

lho de funcionários do quadro próprio da empresa e 25 de empregados terceirizados, conforme dados da Tabela 6:

Os dados das Tabelas 5 e 6 referem-se ao setor de distribuição, que concentra a maior parte dos trabalhadores e das atividades terceirizadas. A Tabela 6 demonstra que, entre 2009 e 2018, na Cemig, o número de mortes de trabalhadores terceirizados foi 16 vezes maior do que o número de mortes de trabalhadores do quadro próprio da empresa. Já na Copel, os empregados contratados de forma terceirizada sofreram 5 vezes mais óbitos do que os do quadro próprio da companhia. Esses números são desproporcionais, se considerarmos que na Copel, em 2016, existiam mais trabalhadores próprios do que terceirizados; e na Cemig, em 2010, o número de trabalhadores terceirizados era ligeiramente maior, cerca de $30 \%$ superior à quantidade de funcionários do quadro próprio.

Entre as causas dessa desproporção, figuram as relações de trabalho precarizadas (o que inclui excesso de trabalho e jornadas extenuantes), a falta de treinamento e qualifica- 
ção técnica defasada e o uso de equipamentos de segurança de pior qualidade, dentre tantas outras formas de deterioração das relações de trabalho flexíveis. Diversos relatos obtidos durante nossa pesquisa confirmam que os trabalhadores terceirizados não recebem o mesmo treinamento que os diretamente contratados pelas estatais e, por isso, sofrem um maior número de acidentes na atividade que, por sua natureza, é de risco.

Segundo o representante dos trabalhadores na Comissão Permanente Nacional de Segurança em Energia Elétrica do Ministério do Trabalho e Emprego (CPNSEE/MTE), o engenheiro Aguinaldo Almeida, os trabalhadores terceirizados trabalham em desigualdade de condições dos contratados diretamente pelas empresas:

Os trabalhadores terceirizados estão mais expostos aos acidentes graves e fatais por vários fatores. Predomina o processo de terceirização selvagem, em que a prioridade é a manutenção do sistema, sem as mesmas condições de trabalho dos profissionais próprios. A maioria dos terceirizados não tem qualificação apropriada, recebe salários medíocres e trabalha 10 ou 12 horas diárias para ganhar horas extras. As condições de trabalho são precárias, com equipamentos adquiridos considerando prioritariamente o custo e não a qualidade e o bem-estar dos trabalhadores. Esses profissionais recebem treinamentos de NR-1010 ${ }^{13}$ muito fracos, apenas para atender a legislação quanto à comprovação por meio de um certificado, participando inclusive de cursos à distância, não atendendo o objetivo previsto pela Norma (Almeida, 2010, p. 38).

Ao se posicionar contra a terceirização das atividades-fim da Copel, um representante sindical dos eletricitários logo fez menção ao maior número de acidentes que esses trabalhadores sofrem e manifestou preocupação em relação ao que vai acontecer futuramente caso a

${ }^{13}$ NR-10 é a Norma Regulamentadora que trata da segurança em instalações e serviços em eletricidade. De acordo com a atualização feita pelo Ministério do Trabalho e Emprego (MTE), em 2004, da portaria que criou a NR-10, em 1978, "esta Norma Regulamentadora - NR estabelece os requisitos e condições mínimas objetivando a implementação de medidas de controle e sistemas preventivos, de forma a garantir a segurança e a saúde dos trabalhadores que, direta ou indiretamente, interajam em instalações elétricas e serviços com eletricidade”. (Brasil, 2004). terceirização continue a crescer. Segundo ele, o sindicato é contrário à terceirização, principalmente, por conta do aumento do número de acidentes:

\begin{abstract}
Os terceirizados sofrem muito mais acidentes do que os trabalhadores primarizados. Então a gente vê com muita expectativa e fica muito esperando pra ver o que vai acontecer com essas atividades, porque é uma coisa que realmente nos preocupa muito. Nós somos contrários (Entrevista 23, realizada com o representante sindical dos trabalhadores da Copel, em dezembro de 2016).
\end{abstract}

O entrevistado acrescentou que os trabalhadores terceirizados não recebem o mesmo treinamento e sofrem um maior número de acidentes na atividade que, por sua natureza, é de risco. Ele ressaltou que "a terceirização leva a uma precarização das condições de trabalho, tendo em vista que esses empregados terceirizados não têm o mesmo treinamento, o mesmo investimento, e a gente pode observar pelos números de acidentes né..." Cabe ressaltar que, para além dos acidentes fatais, muitos são os casos de trabalhadores que têm órgãos mutilados ou amputados e a vida como um todo praticamente invalidada por graves acidentes envolvendo a rede elétrica. Um exemplo disso é o caso do acidente de um jovem de 19 anos à época, que trabalhava como eletricitário terceirizado da Cemig. Devido ao acidente, ele teve queimaduras de terceiro grau em várias partes do corpo, incluindo pernas e coxas, o que resultou na amputação da perna esquerda, além de uma gravíssima lesão na região genital.

Por meio de relatos de familiares de trabalhadores acidentados e mortos, nossa pesquisa constatou que nem as empreiteiras nem as empresas estatais de energia elétrica costumam prestar amparo às vítimas e aos familiares delas dependentes, recusando-se a pagar indenizações. Além de se eximirem da responsabilidade, não raro culpabilizam o próprio trabalhador pelo acidente sofrido, alegando negligência no uso dos equipamentos de segurança. 


\section{CONSIDERAÇÕES FINAIS}

O presente texto analisou algumas dimensões da terceirização e precariedade do trabalho em duas importantes companhias estatais de energia elétrica do Brasil, a Cemig e a Copel. Embora não tenham sido privatizadas, essas empresas foram fortemente impactadas pelos avanços das políticas neoliberais e da hegemonia do capital financeiro no plano internacional, de forma que são crescentemente submetidas a uma lógica cada vez mais voltada à imperativa necessidade de proporcionar lucro aos acionistas privados. Em consequência, a gestão do trabalho passa a ser direcionada pela elevação dos ganhos de produtividade, alcançada à custa de um aumento da terceirização e da flexibilização das formas de contratação da força de trabalho.

Em linhas gerais, nossa pesquisa reafirma a estreita relação entre terceirização e precarização do trabalho já atestada pela literatura, uma vez que os trabalhadores terceirizados da Cemig e da Copel recebem menores salários e benefícios, trabalham mais e possuem uma condição mais instável que os empregados dos quadros próprios dessas empresas. Outras importantes dimensões da precarização do trabalho terceirizado evidenciadas por nossa pesquisa são a maior facilidade de controle sobre o trabalhador terceirizado; o desenvolvimento de mecanismos de resistência, a desస్ peito da maior fragmentação e empecilhos à i luta coletiva que acompanham a terceirização do trabalho; a queda na qualidade do serviço público; e, sobretudo, a maior exposição dos terceirizados a condições que colocam em ris¿. co sua saúde e a própria vida, em relação aos लि trabalhadores contratados diretamente pela empresa. Nesse sentido, os resultados aqui trazidos corroboram aqueles encontrados pelos estudos já existentes: no caso das companhias estatais, especialmente distribuidoras de energia elétrica, a terceirização tem como reflexo mais preocupante um aumento significativo na quantidade de acidentes de trabalho fatais envolvendo os trabalhadores menos qualificados que executam as atividades "de linha de frente".

Acerca desse aspecto, ao adentrarmos no processo concreto de terceirização na Cemig e na Copel, percebemos que as relações de trabalho terceirizadas apontam para uma tendência de precarização e mutilação radical da vida laboral e social desses trabalhadores, pois a iminência da morte, os acidentes e o envelhecimento precoce somam-se aos seus rebaixamentos objetivo e subjetivo. Os relatos de mortes, mutilações, atrasos salariais, assédio moral e constrangimentos no local de trabalho, jornadas de trabalho extenuantes, restrição de direitos, entre outros, nos permitiram ter uma ideia aproximada de como é a realidade dos trabalhadores submetidos a tais condições. Foi possível perceber, portanto, que a terceirização pode ter repercussões muito mais degradantes para eles do que a aparência do fenômeno nos permite enxergar. Recebido para publicação em 20 de março de 2020
Aceito em 6 de julho de 2021

\section{REFERÊNCIAS}

ABRANCHES, S. H. A questão da empresa estatal: economia, política e interesse público. Revista de Administraçã̃o de Empresas, Rio de Janeiro, v. 19, n. 4, p. 95-105, 1979.

ALMEIDA, A. B. Terceirização no Setor Elétrico. [Entrevista cedida a] Cassiana de Oliveira. Revista Proteção. Novo Hamburgo, ano XXIII, ed. 218, p. 38, 2010.

ANTUNES, R. Os Sentidos do Trabalho. 12. reimpressão. São Paulo: Boitempo, 2010.

BRASIL. Ministério do Trabalho e Emprego. Portaria GM n. 598, de 07 de dezembro de 2004. Altera a Norma Regulamentadora $\mathrm{n}^{\mathrm{o}} 10$, que trata de Instalações e Serviços em Eletricidade, aprovada pela Portaria $\mathrm{n}^{\circ} 3.214$, de 1978. Diário Oficinal da União: seção 1, Brasília, DF, n. 235, p. 74-77, 7 dez. 2004. Disponível em: http:// www.trabalhoseguro.com/Portarias/Portaria_598_NR_10_ DOU_08_12_2004.pdf. Acesso em: 29 jul. 2021.

BRAUNERT, M. B. Empresas públicas, racionalidade privada? Um estudo sobre o trabalho nas companhias de economia mista do Paraná. 2018. Tese (Doutorado em Sociologia) - Programa de Pós-Graduação em Sociologia, Universidade Federal do Paraná, Curitiba, 2018.

CHESNAIS, F. A mundialização do capital. São Paulo: Xamã, 1996. 
COMPANHIA ENERGÉTICA DE MINAS GERAIS - Cemig. Quem somos. Minas Gerais, [s. d.]. Disponível em: https:/ www.cemig.com.br/quem-somos/. Acesso em: 31 ago. 2019.

COMPANHIA PARANAENSE DE ENERGIA - Copel. Portal da Transparência. Curitiba, [s. d.]. Disponível em: https://www.copel.com/hpcweb/institucional/portal-datransparencia/. Acesso em: 17 jul. 2021.

COUTINHO, L. M. Apreciação prévia do MPT sobre flagrante de escravidão na Cemig. Repórter Brasil, Belo Horizonte, 20 fev. 2014. Disponível em: http:// reporterbrasil.org.br/2014/02/apreciacao-previa-do-mptsobre-flagrante-de-escravidao-na-cemig/. Acesso em: 26 mar. 2015 .

DAIN, S. Empresa estatal e capitalismo contemporâneo: uma análise comparada. 1980. Tese (Doutorado) - Instituto de Filosofia e Ciências Humanas, Universidade Estadual de Campinas, Campinas, 1980

DEPARTAMENTO INTERSINDICAL DE ESTATÍSTICA E ESTUDOS SOCIOECONÔMICOS - DIEESE. Perfil ocupacional dos empregados do setor de energia elétrica no Brasil: 1998/2004. Estudos e pesquisas, ano 3, n. 28, p. 1-40, 2006 .

DEPARTAMENTO INTERSINDICAL DE ESTATÍSTICA E ESTUDOS SOCIOECONÔMICOS - DIEESE. Terceirização e morte no trabalho: um olhar sobre o setor elétrico brasileiro. Estudos e pesquisas, n. 50, p. 1-18, 2010.

DRUCK, G. A terceirização no setor público e a proposta de liberalização da terceirização pelo PL 4330. Blog da Boitempo, São Paulo, 1 abr. 2015. Dossiê Terceirização. Disponível em: https://blogdaboitempo. com.br/2015/04/01/a-terceirizacao-no-setor-publico-e-aproposta-de-liberalizacao-da-terceirizacao-pelo-pl-4330/. Acesso em: 15 jun. 2017.

. Terceirização: (des)fordizando a fábrica: um estudo do complexo petroquímico. São Paulo: Boitempo, 1999.

Terceirização no serviço público: múltiplas formas de precarizacão do trabalho. In: NAVARRO, V L.; LOURENÇO, E. Â. S. (org.). O avesso do trabalho IV: terceirização, precarização e adoecimento no mundo do trabalho. São Paulo: Outras Expressões, 2017. p. 59-87.

DRUCK, G.; BORGES, Â. Terceirização: o balanço de uma década. Caderno CRH, v. 15, n. 37, p. 111-139, 2002.

FIGUEIREDO, I. S. A terceirização em alta voltagem na Cemig: crônica da degradação do trabalho. 2015. Dissertação (Mestrado em Sociologia) - Instituto de Filosofia e Ciências Humanas, Universidade Estadual de Campinas, Campinas, 2015.
INÁCIO, J. R.; TARDELI, E. A. Sobre saúde e ambiente do trabalho de eletricitários em Minas Gerais. In: NAVARRO, V. L.; LOURENÇO, E. Â. S. (org.). Avesso do trabalho III: saúde do trabalhador e questôes contemporâneas. São Paulo: Outras Expressões, 2013. p. 455-484.

INSTITUTOBRASILEIRODEGEOGRAFIAEESTATÍSTICA. Concla: Comissão Nacional de Classificação. [S. l., s. n.]. Disponível em: https://concla.ibge.gov.br/busca-onlinecnae.html secao $=\mathrm{C} \&$ tipo $=$ cnae $\&$ view $=$ secao. Acesso em: 15 jul. 2021.

KREIN, J. D. Tendências recentes na condição de emprego no Brasil: 1990 - 2005. 2007. Tese (Doutorado em Economia Aplicada) - Instituto de Economia, Universidade Estadual de Campinas, Campinas, 2007.

MARCELINO, P. A administração e a terceirização: como o pragmatismo compromete a análise. In: PADILHA, V. (org.). Antimanual de gestão: desconstruindo os discursos do management. São Paulo: Ideias \& Letras, 2015. p. 91126.

A logística da precarização: terceirização do trabalho na Honda do Brasil. 2002. Dissertação (Mestrado) - Instituto de Filosofia e Ciências Humanas, Universidade Estadual de Campinas, Campinas, 2002.

Terceirização e ação sindical: a singularidade da reestruturação do capital no Brasil. 2008. Tese (Doutorado) - Instituto de Filosofia e Ciências Humanas, Universidade Estadual de Campinas, Campinas, 2008.

RAMALHO, J. R. Precarização do trabalho e impasses da organização coletiva no Brasil. In: ANTUNES, R. et al. Neoliberalismo, trabalho e sindicatos: reestruturação produtiva no Brasil e na Inglaterra. São Paulo: Boitempo, 1997. p. 85-114.

SCOPINHO, R. A. Privatização, reestruturação e mudanças nas condições de trabalho: o caso do setor de energia elétrica. Cadernos de Psicologia Social do Trabalho, São Paulo, v. 5, p. 19-36, 2002

VALENTE, M. A terceirização dos serviços públicos: trabalho decente e serviço público de qualidade. In: DAU, D. M.; RODRIGUES, I. J.; CONCEIĈ̃A, J. J. (org.). Terceirização no Brasil: do discurso da inovação à precarização do trabalho (atualização do debate e perspectivas). São Paulo: Annablube, 2009. p. 103-206.

VIEIRA, J. P. Antivalor: um estudo da energia elétrica: construída como antimercadoria e reformada pelo mercado nos anos 1990. São Paulo: Paz e Terra, 2007. 


\section{OUTSORCING AND PRECARIOUSNESS IN BRAZIL'S ELECTRIC SECTOR}

\author{
Mariana Bettega Braunert \\ Igor Silva Figueiredo
}

This study analyzes some outsourcing and job precariousness aspects in two important Brazilian state-owned electricity companies: Cemig (MG) and Copel (PR). By analyzing the quantitative and qualitative data obtained through interviews conducted with workers and union leaders, we observed an increase in indirect hiring, one of the main strategies adopted to reduce costs and increase productivity. Among the many aspects related to the precariousness of outsourced work, such as lower wages and weakening of collective bargains, we highlight the increase in the number of work accidents, revealing itself the most worrisome aspect of the outsourcing process in activities that, by their very nature, put workers at high risk, such as those carried out by companies in the electric sector.

Keywords: Electric Sector. State Companies. Outsourcing. Precariousness. Work Accidents.

\section{EXTERNALISATION ET PRÉCARITÉ DANS LE SECTEUR ÉLECTRIQUE BRÉSILIEN}

\author{
Mariana Bettega Braunert \\ Igor Silva Figueiredo
}

Cette étude analyse certains aspects de l'externalisation et de la précarité de l'emploi dans deux importantes entreprises publiques d'électricité au Brésil: Cemig (MG) et Copel (PR). En analysant les données qualitatives et quantitatives obtenues lors des interviews menés avec les travailleurs et les dirigeants syndicaux, on a observé une augmentation de la sous-traitance, l'une des principales stratégies adoptées pour réduire les dépenses et augmenter la productivité. Parmi les nombreux aspects liés à la précarité de l'externalisation, tels que la baisse des salaires et l'affaiblissement des luttes collectives, on souligne l'augmentation du nombre d'accidents au travail, se révélant l'aspect le plus préoccupant du processus d'externalisation dans les activités qui, par leur nature même, exposent les travailleurs à un risque élevé, comme celles réalisées par les entreprises du secteur électrique.

Mots-CLÉs: Secteur électrique. Entreprises publiques. Externalisation. Précarité. Accidents au travail.

Mariana Bettega Braunert - Doutora em Sociologia pelo Programa de Pós-Graduação em Sociologia da Universidade Federal do Paraná (UFPR) e Mestre em Sociologia pela mesma instituição. Professora do curso de Administração Pública da UFPR Setor Litoral. Possui graduação em Ciências Sociais pela UFPR e em Direito pelo Centro Universitário Curitiba (UniCuritiba). Atualmente realiza estágio de pósdoutorado no Programa de Pós-Graduação em Sociologia (PPGS/UFPR) e é membro do Grupo de Estudos Trabalho e Sociedade (GETS/UFPR). Possui publicações de artigos em revistas qualificadas sobre elites políticas, flexibilidade das formas de contratação no setor de tecnologia da informação e relações de trabalho no setor público.

Igor Silva Figueiredo - Doutor em Ciências Sociais pelo Programa de Pós-Graduação em Ciências Sociais da Universidade Estadual de Campinas (Unicamp), Mestre em sociologia e Especialista em Economia do Trabalho e Sindicalismo pela mesma instituição. Possui trabalhos e pesquisas em sociologia do trabalho, principalmente sobre os temas da terceirização e da precarização do trabalho. Atualmente é professor das disciplinas de sociologia e ciência política da Faculdade de Direito de Itu (Faditu). 